\title{
RESEARCH
}

Open Access

\section{Trichostatin A ameliorates Alzheimer's disease-related pathology and cognitive deficits by increasing albumin expression and $A \beta$ clearance in APP/PS1 mice}

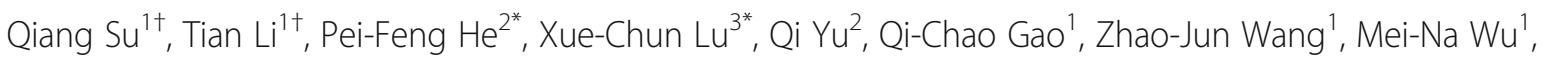
Dan Yang ${ }^{1}$ and Jin-Shun $\mathrm{Qi}^{i^{*}}$

\begin{abstract}
Background: Alzheimer's disease (AD) is an intractable neurodegenerative disorder in the elderly population, currently lacking a cure. Trichostatin A (TSA), a histone deacetylase inhibitor, showed some neuroprotective roles, but its pathology-improvement effects in $A D$ are still uncertain, and the underlying mechanisms remain to be elucidated. The present study aims to examine the anti-AD effects of TSA, particularly investigating its underlying cellular and molecular mechanisms.

Methods: Novel object recognition and Morris water maze tests were used to evaluate the memory-ameliorating effects of TSA in APP/PS1 transgenic mice. Immunofluorescence, Western blotting, Simoa assay, and transmission electron microscopy were utilized to examine the pathology-improvement effects of TSA. Microglial activity was assessed by Western blotting and transwell migration assay. Protein-protein interactions were analyzed by coimmunoprecipitation and LC-MS/MS.

Results: TSA treatment not only reduced amyloid $\beta(A \beta)$ plaques and soluble $A \beta$ oligomers in the brain, but also effectively improved learning and memory behaviors of APP/PS1 mice. In vitro study suggested that the improvement of A $\beta$ pathology by TSA was attributed to the enhancement of $A \beta$ clearance, mainly by the phagocytosis of microglia, and the endocytosis and transport of microvascular endothelial cells. Notably, a meaningful discovery in the study was that TSA dramatically upregulated the expression level of albumin in cell culture, by which TSA inhibited A $\beta$ aggregation and promoted the phagocytosis of A $\beta$ oligomers.
\end{abstract}

Conclusions: These findings provide a new insight into the pathogenesis of AD and suggest TSA as a novel promising candidate for the AD treatment.

Keywords: Trichostatin A, APP/PS1 mice, Amyloid $\beta$ clearance, Learning and memory, Albumin, Microglia

\footnotetext{
*Correspondence: jinshunqi2009@163.com; hepeifeng2006@126.com;

luxuechun@126.com

${ }^{\dagger}$ Qiang Su and Tian Li contributed equally to this work.

'Department of Physiology, Key Laboratory of Cellular Physiology, Ministry of

Education, Shanxi Medical University, Taiyuan 030001, Shanxi, China

${ }^{2}$ Institute of Medical Data Sciences and School of Management, Shanxi

Medical University, Taiyuan 030001, Shanxi, China

${ }^{3}$ Department of Hematology, the Second Medical Center \& National Clinical Research Center for Geriatric Diseases, Chinese PLA General Hospital, Beijing 100853, China
}

(c) The Author(s). 2021 Open Access This article is licensed under a Creative Commons Attribution 4.0 International License, which permits use, sharing, adaptation, distribution and reproduction in any medium or format, as long as you give appropriate credit to the original author(s) and the source, provide a link to the Creative Commons licence, and indicate if changes were made. The images or other third party material in this article are included in the article's Creative Commons licence, unless indicated otherwise in a credit line to the material. If material is not included in the article's Creative Commons licence and your intended use is not permitted by statutory regulation or exceeds the permitted use, you will need to obtain permission directly from the copyright holder. To view a copy of this licence, visit http://creativecommons.org/licenses/by/4.0/ The Creative Commons Public Domain Dedication waiver (http://creativecommons.org/publicdomain/zero/1.0/) applies to the data made available in this article, unless otherwise stated in a credit line to the data. 


\section{Background}

Alzheimer's disease (AD), a chronic neurodegenerative disease, is the most common cause of dementia in elderly individuals. According to World Alzheimer Report, dementia afflicts more than 47 million people worldwide, and this number will increase to 152 million by 2050 [1], while in which AD accounts for about $60-80 \%$ [2]. Unfortunately, there is still lack of efficient therapeutic drugs to reverse the progression of AD. It is well known that amyloid $\beta(\mathrm{A} \beta)$ accumulated in the brain is a key neuropathological hallmark of $\mathrm{AD}$, leading to synaptic dysfunction and neuronal apoptosis $[3,4]$. A $\beta$ is produced from the sequential cleavage of amyloid precursor protein (APP) by $\beta$-secretase and $\gamma$-secretase $[5,6]$. The imbalance between the production and clearance of $A \beta$ has been considered as the major cause of excessive aggregation of neurotoxic $A \beta$ in the brain $[7,8]$. Since $A \beta$ production and accumulation is an inevitable consequence in the progression of $\mathrm{AD}$, targeting the clearance of $\mathrm{A} \beta$ in the brain of $\mathrm{AD}$ patients becomes a potential therapeutic strategy for $A D$. Intracellular $A \beta$ can be cleared mainly through ubiquitin-proteasome pathway (UPP) and autophagy-lysosome pathway (ALP), while extracellular $A \beta$ is degraded by multiple proteases such as neprilysin (NEP) and insulin-degrading enzyme (IDE) [9] and microglial phagocytosis [10]. Additionally, A $\beta$ can be transported out of the brain and ultimately cleared by blood components, or some tissues and organs in periphery. Although many researchers reported their results on $A \beta$ clearance, the detailed mechanisms underlying $A \beta$ clearance are still not fully elucidated, and the drugs that could effectively remove $A \beta$ remain to be further explored.

Drug repurposing referred to rediscovering a new indication for an existing drug [11]. In the current study, our group took such a strategy and found that trichostatin A (TSA) might be a potential therapeutic drug for AD. TSA, an inhibitor of histone deacetylase (HDAC) [12], is currently for anti-tumor therapy [13, 14]. Interestingly, the drug TSA showed neuroprotective effects in some experimental studies. For example, an animal study showed that short-term treatment of TSA by intraperitoneal injection improved conditioned fear memory and hippocampal CA3-CA1 long-term potentiation (LTP) and upregulated the level of hippocampal histone $\mathrm{H} 4$ acetylation in APP/PS1 mice, indicating that TSA could pass through the $\mathrm{BBB}$ and exert neuroprotective effects [15]. Another experiment showed that TSA increased the levels of plasma gelsolin and $A \beta$ in $A D$ transgenic mice, suggesting that plasma gelsolin might help to clear $A \beta$ from the brain or other tissues [16]. Furthermore, it was found that TSA also increased gelsolin expression in the brain and prevented the formation of new amyloid deposits, but increased the size of existing plaques [17]. In addition, a recent study showed that TSA attenuated A $\beta$-induced cytotoxicity of $\mathrm{SH}$ SY5Y cells by activating nuclear factor erythroid 2related factor 2 (Nrf2) signaling [18]. However, there is still a lack of a systematic research on the effects of TSA in ameliorating cognitive deficits and pathological damage of APP/PS1 mice. Especially, the molecular mechanisms underlying the neuroprotection of TSA remain to be clarified. In the present study, we reported the ameliorative effects of chronic intraperitoneal (i.p.) injection of TSA on the short-term recognition memory and long-term spatial memory of APP/PS1 mice by using multiple behavioral tests. Furthermore, we examined the $\mathrm{A} \beta$ clearance effects of TSA in the brain and peripheral blood in APP/PS1 mice and the molecular mechanisms underlying the $A \beta$ clearance by TSA.

\section{Methods \\ Animals}

Male APPswe/PS1dE9 (APP/PS1) heterozygous mice and wild-type (WT) littermates were used in the present in vivo study. The APP/PS1 mice expressed human APP with Swedish mutations (K595N/M596L) and human PS1 gene with deletion of exon 9. All mice were obtained from the Model Animal Research Center of Nanjing University (Nanjing, China) and genotyped through tail clips and subsequent PCR analysis of genomic DNA. Mice were housed in a temperature-regulated room under a $12 \mathrm{~h}$ light- $12 \mathrm{~h}$ dark cycle, with free access to food and water. The 8-month-old mice $(n=44)$ were randomly divided into four groups: WT + vehicle $(n=11), \quad \mathrm{WT}+\mathrm{TSA} \quad(n=11), \quad \mathrm{APP} / \mathrm{PS} 1+$ vehicle $(n=11)$, and APP/PS1 + TSA $(n=11)$. Based on a previous study [15], TSA (T6270, TargetMol) was solubilized in 100\% dimethylsulfoxide (DMSO) and then diluted with normal saline to final concentration of $0.2 \mathrm{mg} / \mathrm{mL}$. TSA $(2 \mathrm{mg} / \mathrm{kg})$ or equivalent vehicle (solvent of TSA) was administered via i.p. injection daily for 30 days before behavioral experiments. The injection was continued during behavioral experiments and kept until 2 weeks after the end of behavioral experiment (see Fig. S1).

\section{Novel object recognition test}

Twenty-four hours after the open field test, the mice were subjected to a novel object recognition test to assess the short-term recognition memory of mice. As described previously [19], mice were firstly placed into the open field with two identical objects (object 1 and object 2) for familiarization. After a $6 \mathrm{~h}$ retention interval, mice were returned to the same open field for test, but one familiar object had been replaced by a novel object with different color and shape. In the either phase, each mouse was placed in the apparatus facing the wall and allowed to freely explore the objects for $10 \mathrm{~min}$. The apparatus was washed with $75 \%$ ethanol solution before 
each trial. The behavior of mice was recorded by a video tracking system and analyzed using SMART 3.0 software (RWD Life Science). Novel object recognition memory was calculated as the "novel object recognition index" $(\mathrm{NOI})=($ exploration time of novel object $) /($ exploration time of familiar and novel objects) $\times 100 \%$.

\section{Morris water maze test}

Morris water maze (MWM) test was used to assess the long-term spatial learning and memory ability of mice [20]. Briefly, MWM test was performed in a white circular tank (120 cm in diameter, $50 \mathrm{~cm}$ in height), filled with tap water $\left(22 \pm 3{ }^{\circ} \mathrm{C}\right)$ and divided into four equal virtual quadrants. Non-toxic white paint was added into the water until it became opaque. Some different geometric cues were mounted on the white curtain surrounding the tank. In the place navigation training phase (four 60$\mathrm{s}$ trials/day for five consecutive days), a circular escape platform $(10 \mathrm{~cm}$ in diameter) was placed in the center of a targeted quadrant, submerged $1 \mathrm{~cm}$ beneath the surface of the water. Each mouse was placed in the water facing the wall of the tank from different release positions and allowed to search for the escape platform. Once the mouse escaped onto the platform, it was allowed to remain on the platform for $5 \mathrm{~s}$. The escape latency to climb onto the escape platform was recorded. If the mouse failed to find the platform within $60 \mathrm{~s}$, it was guided to climb on the platform and remained on it for $30 \mathrm{~s}$. On the 6th day of probe test, mice were allowed to swim freely in the water without the platform for $60 \mathrm{~s}$. The percentage of time spent in the target quadrant and the number of platform crossing were measured. Mice that floated in the maze were not enrolled in the test. Lastly, a visible platform test was performed to detect the visual ability of mice. The swimming speed was also measured during the MWM test to exclude the mice with motor deficits. The swimming tracks were monitored and analyzed by a computer-based video tracking system (Ethovision software, Noldus Information Technology).

\section{Tissue processing and antibodies}

After 2 weeks recovery from behavioral experiments, the mice in each group were randomly divided into two cohorts, one for immunofluorescence staining and the other for single molecule array (Simoa) and Western blot (WB). After deeply anesthetized with 5\% chloralhydrate $(0.007$ $\mathrm{mL} / \mathrm{g}$, i.p.), mice blood was collected via cardiac puncture. Plasma was separated by centrifugation at $5000 \times g$ for 15 min at $4{ }^{\circ} \mathrm{C}$ and immediately stored at $-80^{\circ} \mathrm{C}$. For immunofluorescence staining, mice were perfused transcardially with $0.01 \mathrm{M}$ phosphate buffer saline (PBS) and subsequently with $4 \%$ paraformaldehyde (PFA). Afterwards, the brains were isolated and successively immersed in $4 \%$ PFA $(24 \mathrm{~h}), 15 \%$ sucrose $(24 \mathrm{~h})$, and then $30 \%$ sucrose $(48 \mathrm{~h})$. Serial coronal sections ( $30 \mu \mathrm{m}$ thick) were cut using a cryomicrotome (CM1950, Leica) and mounted on polylysine-coated slides. For Simoa and WB, mice were perfused through the hearts with $30 \mathrm{ml}$ saline solution $(0.9 \%)$ and rapidly decapitated, and then the brains were immediately removed. The hippocampus tissues were carefully dissected out on ice and immediately frozen in liquid nitrogen and then kept in a $-80{ }^{\circ} \mathrm{C}$ freezer.

The primary antibodies used in the study include the following: 6E10 (803015, Biolegend), D54D2 (8243, Cell Signaling), anti-LC3B (3868, Cell Signaling), anti-Iba 1 (019-19741, Wako), anti-APP-CTF (A8717, Sigma-Aldrich), anti-IDE (ab133561, Abcam), anti-p62 (ab109012, Abcam), anti-NEP (ab81688, Abcam), anti-ubiquitin (ab134953, Abcam), antiBACE1 (ab2077, Abcam), anti-LRP1 (ab92544, Abcam), antiBeclin 1 (ab207612, Abcam), anti-albumin (ab207327, Abcam), anti-ace-Histone H4 (Ac-H4) (ab177790, Abcam), and anti- $\beta$-actin (D191047, Sangon Biotech). The secondary antibodies include goat anti-rabbit IgG-HRP conjugate (BA1054, BOSTER), goat anti-mouse IgG-HRP conjugate (BA1050, BOSTER), goat anti-mouse IgG-Cy3 (BA1031, BOSTER), and goat anti-rabbit IgG-Cy3 (BA1032, BOSTER).

\section{Immunofluorescence and Thioflavin S (ThioS) staining}

Brain slices were washed in PBS, permeabilized for $15 \mathrm{~min}$ by shaking at room temperature with PBS containing $0.5 \%$ Triton X-100, rinsed in PBS, and then blocked with 5\% bovine serum albumin (BSA; AR1006, BOSTER) in PBS for $1 \mathrm{~h}$ at room temperature. Thereafter, sections were incubated overnight at $4{ }^{\circ} \mathrm{C}$ with primary antibody and then placed in a wet box containing a little water. After rinsing, sections were incubated with appropriate fluorescenceconjugated secondary antibodies at room temperature for $1 \mathrm{~h}$. For ThioS staining, sections were stained with $0.05 \%$ ThioS (23059, AAT Bioquest) in 50\% ethanol in dark for $8 \mathrm{~min}$ at room temperature, followed by two rinsing in $80 \%$ ethanol for $10 \mathrm{~s}$ each. Finally, DAPI (C0065, Solarbio) was used for nuclear staining. Slides were then sealed with the fluorescent mounting medium (AR1109, BOSTER). Immunofluorescence images were acquired using a fluorescent microscope (Olympus) and analyzed using the ImageJ software.

\section{Western blot (WB)}

Hippocampal tissues were prepared as described above. Cells (see below) were washed twice with ice-cold PBS. The tissues and cells were homogenized in cold RIPA buffer (AR0102, BOSTER) containing a cocktail of PMSF (AR1179, BOSTER) and protein phosphatase inhibitor (AR1183, BOSTER). The homogenates were then centrifuged $\left(16,000 \times g, 30 \mathrm{~min}, 4{ }^{\circ} \mathrm{C}\right)$, and the supernatants were collected. The total protein concentrations of the samples were measured by a BCA Protein Assay Kit 
(PC0020, Solarbio). Total protein for each sample was diluted 1:1 with loading buffer (AR0131, BOSTER) and boiled for $5 \mathrm{~min}$ at $95^{\circ} \mathrm{C}$. Equal amounts of total protein were separated by $12 \%$ or $15 \%$ SDS-PAGE (AR0138, BOSTER) and transferred to PVDF membranes $(0.45 \mu \mathrm{m}$ or $0.22 \mu \mathrm{m}$, Millipore). Following blocking with 5\% BSA for $2 \mathrm{~h}$ at room temperature, the membranes were incubated with desired primary antibodies overnight at $4{ }^{\circ} \mathrm{C}$, and then HRP-conjugated secondary antibody for another $2 \mathrm{~h}$ at room temperature. After several washes, the protein bands were developed with ECL Western Blot Detection kit (P0018FS, Beyotime) and detected using Azure c300 Chemiluminescent Western Blot Imaging System (Azure Biosystems). The band intensity was analyzed with AlphaView SA (Fluorchem FC3, ALPHA).

\section{Single molecule array (Simoa) assay for quantification of $A \beta_{40}$ and $A \beta_{42}$}

The concentrations of $A \beta_{40}$ and $A \beta_{42}$ in the hippocampus and plasma were quantified using the commercially available Neurology 3-Plex Assay Kits (101995, Quanterix) on a Simoa platform (HD-1 Analyzer, Quanterix) according to the instructions by the manufacturer. Samples were diluted at a ratio of 1:4 and performed on a single run.

\section{Cell culture and reagent preparation}

Murine hippocampal neuronal cell line (HT22) and murine neuroblastoma cell line (N2a) were respectively provided by the Department of Physiology and Department of Anatomy, Shanxi Medical University. Murine microglia cell line (BV2) was bought from the cell bank (Chinese Academy of Medical Sciences). Murine microvascular endothelial cell line (bEnd.3) was purchased from iCell Bioscience Inc. (China). Cells were cultured at $37^{\circ} \mathrm{C}$ in a humidified $5 \% \mathrm{CO}_{2}$ incubator and were maintained in DMEM media supplemented with $10 \%$ fetal bovine serum (FBS, ExCell) and antibiotics $(100 \mathrm{U} / \mathrm{mL}$ penicillin and $100 \mu \mathrm{g} / \mathrm{mL}$ streptomycin). For morphological observation and Western blot, cells were seeded at a proper density into a 6-well plate and treated under the indicated conditions for $24 \mathrm{~h}$, and then the protein extract was collected.

Recombinant $A \beta_{1-42}$ peptide (ChinaPeptides) was dissolved in HFIP, sonicated for $30 \mathrm{~min}$, aliquoted, lyophilized, and stored at $-80^{\circ} \mathrm{C}$ until use. Lyophilized $A \beta$ was resuspended in DMSO and diluted in PBS to the final concentration $(10 \mu \mathrm{M}$ and $20 \mu \mathrm{M})$. Albumin powder (30R-3304, Fitzgerald) was dissolved in PBS to the final concentrations of $10 \mu \mathrm{M}$ and $20 \mu \mathrm{M}$. ITSA-1 (S8323, Selleck) powder was dissolved in DMSO and diluted in $\mathrm{PBS}$ to the final concentration of $50 \mu \mathrm{M}$.

\section{Transmission electron microscopy (TEM)}

The morphological changes of $A \beta$ aggregation in the presence or absence of albumin were characterized by TEM according to a previously published method [21]. Freshly dissolved $\mathrm{A} \beta(20 \mu \mathrm{M})$ was treated with albumin $(20 \mu \mathrm{M})$ and incubated at $37^{\circ} \mathrm{C}$ for $24 \mathrm{~h}$ with constant agitation. Glow discharged grids were treated with samples $(5 \mu \mathrm{L})$ for $2 \mathrm{~min}$ at room temperature. The excess sample was removed with filter paper and then negatively stained with $1 \%$ phosphotungstic acid for $1 \mathrm{~min}$. Phosphotungstic acid was blotted off and the grid was dried for $20 \mathrm{~min}$ at room temperature. Images were recorded on a JEM-1011 electron microscope (JEOL) at the voltage of $80 \mathrm{kV}$.

\section{Cell migration assay}

Cell migration was detected using an $8-\mu \mathrm{m}$ pore size culture insert (Corning) in a 24-well plate to assess the migration of BV2 cells. BV2 cells were suspended in standard medium and added in the upper chamber of the transwell system, and conditioned medium (contained $A \beta$ $(10 \mu \mathrm{M})$ or albumin $(10 \mu \mathrm{M})$ or both) was added into the lower chamber. After $24 \mathrm{~h}$ incubation, cells migrating to the underside were fixed with 4\% PFA and then stained with DAPI and counted at $\times 20$ magnification with an immunofluorescence microscope (Olympus).

\section{Statistical analysis}

SPSS 13.0 and SigmaPlot 12.3 were used for the statistical analysis. The escape latency and swimming speed in the MWM test were analyzed by two-way ANOVA with repeated measures followed by post hoc Tukey's multiple comparison tests. The other data were assessed by unpaired Student's $t$ test or one-way ANOVA followed by the appropriate post hoc test. All data were presented as means \pm standard error (SEM) with $p<$ 0.05 considered as statistically significant.

\section{Results}

TSA ameliorated recognition memory and spatial memory of APP/PS1 mice

Novel object recognition test was firstly used to examine whether TSA could ameliorate recognition memory of APP/PS1 mice (Fig. 1a). In the familiarization phase (Fig. 1b), no difference in the exploration time for two identical objects was found among all groups $(p>0.05)$. During the test phase (Fig. 1c), the NOI in vehicletreated APP/PS1 mice was significantly lower than that in vehicle-treated WT mice $(p<0.01)$, while TSA treatment basically reversed this decline in the APP/PS1 + TSA mice $(p<0.05)$. In addition, we noticed that TSA alone (WT + TSA) also markedly elevated NOI compared to vehicle-treated WT mice $(p<0.001)$. These results indicated that TSA treatment could mitigate the 

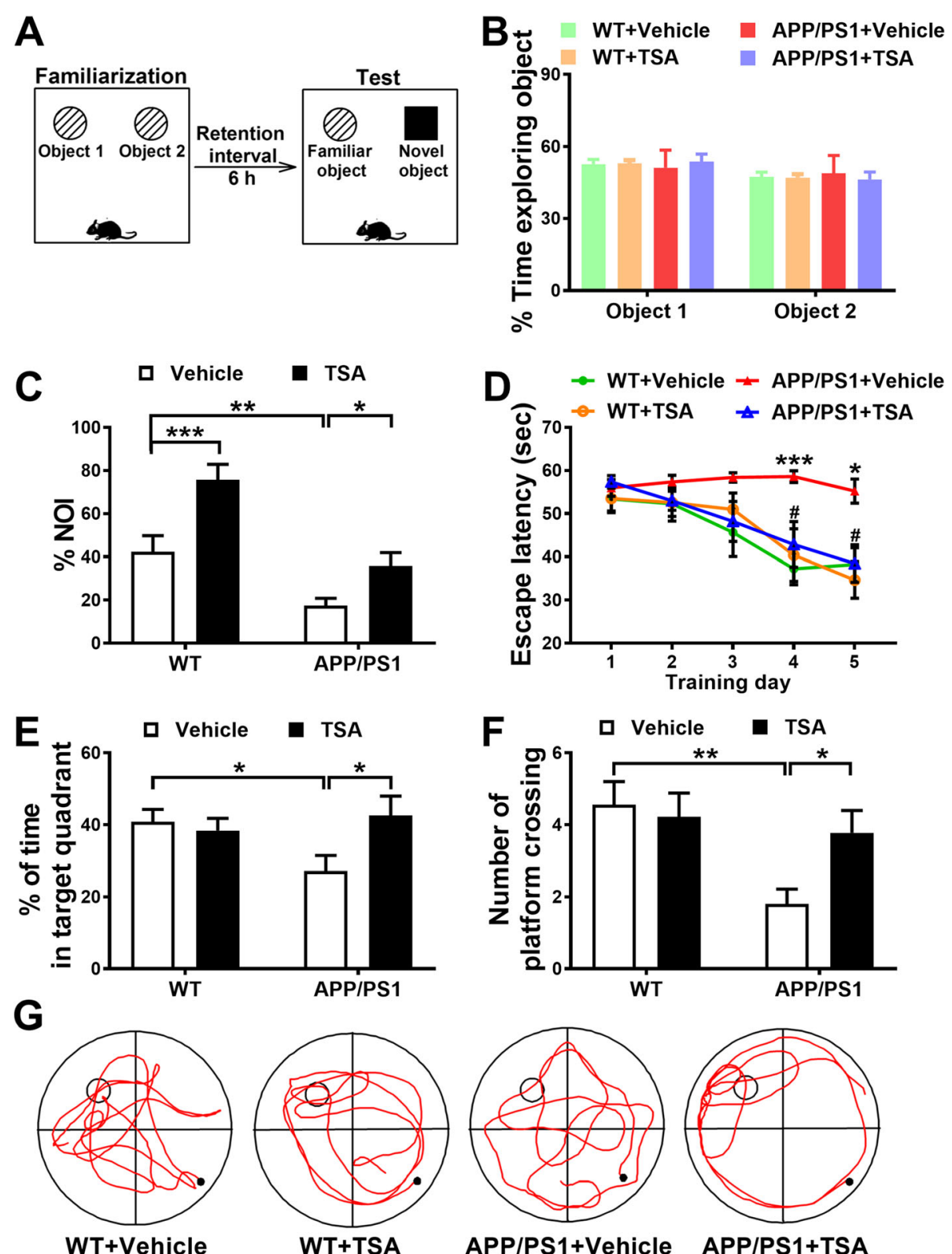

Fig. 1 TSA treatment improved recognition memory and spatial learning and memory of APP/PS1 mice. a Schematic of the NORT. $\mathbf{b}$ The percentage of time exploring two identical objects (object 1 and object 2) during familiarization phase. c Novel object recognition index (NOI) during test phase in NORT. d Plots showing the changes of escape latency of mice to find the hidden platform during place navigation training phase. *vs WT + vehicle, \#vs APP/PS1 + vehicle. e Histograms showing the percentage of swimming time of mice spent in the target quadrant. $\mathbf{f}$ Histograms showing the number of platform crossing in the probe test. $\mathbf{g}$ Representative trajectories of each group in the probe test. $n=9-10$ in each group. ${ }^{*} p<0.05,{ }^{* *} p<0.01,{ }^{* * *} p<0.001$ and ${ }^{*} p<0.05$

recognition memory deficits of APP/PS1 mice. Further, the MWM test was performed to evaluate the effects of TSA on the spatial learning and memory in APP/PS1 mice. As shown in Fig. 1d, the escape latency of vehicletreated APP/PS1 mice was markedly longer on training day $4(p<0.001)$ and day $5(p<0.05)$, while TSA treatment significantly shorten the escape latency of APP/ PS1 mice on day $4(p<0.05)$ and day $5(p<0.05)$, implying that TSA relieved the spatial learning deficit in APP/
PS1 mice. In the probe test, the mice in APP/PS1 + vehicle group exhibited significant reductions in the percentage of swimming time in the target quadrant $(p<0.05)$ and the number of platform crossing $(p<0.01)$ compared with WT + vehicle group, whereas the reductions were reversed in APP/PS1 + TSA group $(p<0.05)$ (Fig. 1e, f), indicating that TSA effectively improved the spatial reference memory of APP/PS1 mice. In the visible platform test, the escape latency to reach the 
platform and the swimming speed of all mice did not show any significant difference among all groups $(p>$ 0.05 ) (Fig. S2A and B), suggesting that the differences in performance among groups of mice in hidden platform and probe tests were not due to the changes in the visual acuity and swimming ability of mice.

\section{TSA reduced both $A \beta$ plaques and $A \beta$ oligomers in the} hippocampus, as well as A $\beta$ levels in the plasma of APP/ PS1 mice

Given that $A \beta$ plaque is one important neuropathological hallmark in AD brains [22], we firstly evaluated whether TSA affected $A \beta$ plaques in the hippocampus of APP/PS1 mice by Thioflavin $S$ (ThioS) staining and A $\beta$ immunostaining (6E10). Clearly, neither ThioS- nor 6E10-positive plaque was found in the WT mice (Fig. 2a), supporting the results of no gene mutation in WT mice. Nevertheless, a widespread distribution of ThioS- and 6E10-positive plaques was evidently observed in the hippocampus of APP/PS1 mice, with good overlap of two images, while TSA treatment significantly reduced both number and area of the $A \beta$ immunoreactive plaques in the hippocampus of APP/PS1 mice $(p<0.05)$ (Fig. 2b, c). Next, we measured soluble neurotoxic $A \beta$ oligomers with Western blot using 6E10 and D54D2 antibodies (Fig. S3A). Similar to immunostaining results, higher levels of 6E10 and D54D2 immunopositive blots around $10 \mathrm{kDa}$ (presumably $\mathrm{A} \beta$ oligomers) were found in the hippocampus of vehicle-treated APP/PS1 mice than vehicle-treated WT mice (6E10: $p<0.01$, D54D2: $p<0.001$ ), while the increase in the presumable $\mathrm{A} \beta$ oligomer was significantly reduced in TSA-treated APP/ PS1 mice (6E10: $p<0.05$, D54D2: $p<0.001$ ) (Fig. S3B and $C$ ). Furthermore, by using Simoa assay, we justified that TSA noticeably downregulated the levels of soluble $\mathrm{A} \beta_{40}(p<0.01)$ and $\mathrm{A} \beta_{42}(p<0.05)$ in the hippocampal homogenates of APP/PS1 mice (Fig. 2d). These data strongly demonstrated that TSA diminished both insoluble $A \beta$ deposition and soluble $A \beta$ in the hippocampus of APP/PS1 mice. Besides, TSA also suppressed microgliosis in the hippocampus of APP/PS1 mice (Fig. S3D-F and see Supplementary Results).

As the level of $A \beta$ in the brain is dependent on the dynamic equilibrium between $A \beta$ production and $A \beta$ clearance, the TSA-induced $A \beta$ reduction might resulted from $A \beta$ production inhibition or $A \beta$ clearance enhancement. However, our further examination showed TSA did not affect $A \beta$ production, because it did not change the levels of full-length APP (flAPP), $\beta$-secretase (BACE1), and C-terminal APP fragments (CTF) $(p>$ 0.05) (Fig. S4A and C-F). Meanwhile, the levels of IDE and NEP, two major hydrolytic enzymes for degrading extracellular $\mathrm{A} \beta$, also did not change by TSA $(p>0.05)$ (Fig. S4B and G-H), suggesting that TSA did not promote $A \beta$ extracellular degradation. In contrast, intracellular ubiquitin-proteasome pathway, not autophagy, was involved in TSA-induced removal of $A \beta$ in the brain (Fig. S5A-F and see supplementary results).

Since removal of $A \beta$ from blood can reduce the $A \beta$ levels in the brain [23], we also examined whether TSA treatment affected peripheral A $\beta$ clearance in APP/PS1 mice. The results of Simoa assay demonstrated that TSA treatment evidently lowered both $\mathrm{A} \beta_{40}(p<0.01)$ and $\mathrm{A} \beta_{42}$ levels $(p<0.05)$, as well as their total level $(p<$ 0.01 ) in the plasma of APP/PS1 mice (Fig. 2e), implying that TSA might also promote peripheral clearance of $A \beta$ in the APP/PS1 mice. Since the low-density lipoprotein receptor-related protein 1 (LRP1), as the primary receptor, plays a role in transporting $A \beta$ across the $B B B$ into periphery, we further examined the expression level of LRP1 in the hippocampus. As shown in Fig. S5H, there was no difference in the levels of LRP1 among four groups $(p>0.05)$, indicating that the TSA-induced A $\beta$ removal from brain was not mediated by LRP1.

TSA, by promoting the combination of albumin with $A \beta$, enhanced $A \beta$ transport toward the periphery and $A \beta$ endocytosis in the endothelial cell

Based on the above results, supposing that the clearance and transport of $A \beta$ might be mediated through binding with other proteins, we performed Co-IP and LC-MS/ MS to identify the proteins that interacted with $A \beta$ in the hippocampus of APP/PS1 mice. We found that, in the candidates identified by LC-MS/MS, the substance most close to the molecular size in the band of SDSPAGE gel was albumin (Fig. S6A and see Supplementary Results). So we speculated that the interaction between $A \beta$ and albumin might exist in the hippocampus of APP/PS1 mice. To justify this hypothesis, we further performed an immunofluorescence double-staining experiment and found an obvious co-localization of $A \beta$ plaque and albumin in the hippocampal sections of APP/PS1 mice (Fig. 3a). Moreover, the albumin expression decreased with the reduction of $A \beta$ plaques after TSA treatment. Additionally, the results of Co-IP further confirmed that there was an interaction between albumin and A $\beta$ in the hippocampus of APP/PS1 mice (Fig. $\mathrm{S} 6 \mathrm{~B})$. Altogether, these results indicated that albumin might be involved in TSA-induced A $\beta$ clearance in APP/ PS1 mice.

In view of albumin as an important transporter in the body [24], we speculated that the central $A \beta$ clearance by TSA is most likely the result of albumin combining $A \beta$ and transporting it outwards. Next, we examined the distribution of albumin- $\mathrm{A} \beta$ complexes in the brain by immunofluorescence double staining. As shown in Fig. $3 \mathrm{~b}$, albumin- $A \beta$ complexes were indeed scattered in the brain tissues and blood vessels of APP/PS1 mice. 


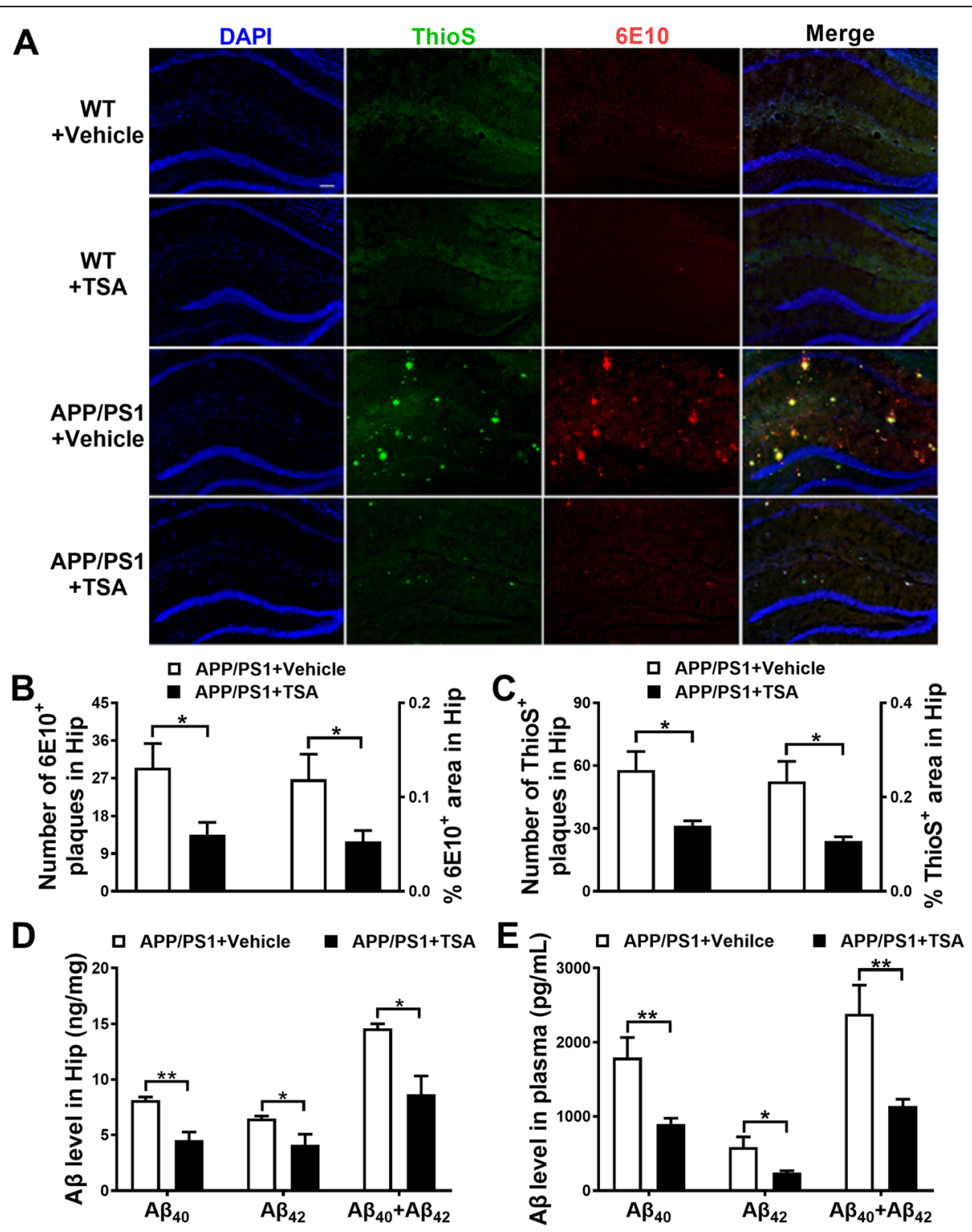

Fig. 2 TSA treatment reduced AB level in the hippocampus and plasma of APP/PS1 mice. a Representative images showing A $\beta$ plaques in the hippocampus of mice. Thioflavin S (ThioS), green; 6E10, red; DAPI, blue. Scale bar, $200 \mu \mathrm{m}$. $\mathbf{b}$ Histograms showing the number of 6E10-positive A plaques in the hippocampus (Hip). $\mathbf{c}$ Histograms showing the percent area of ThioS-positive A $\beta$ plaques in the hippocampus (Hip). $n=6$ per group. $\mathbf{d}$, e Simoa assay for the levels of $A \beta_{40}$ and $A \beta_{42}$ in the hippocampus (Hip) (d) and plasma (e) of APP/PS1 mice treated with vehicle or TSA. $n=4$ per group. ${ }^{*} p<0.05$ and ${ }^{* *} p<0.01$

Moreover, the complexes around the blood vessels of cerebral falx increased with the decrease of $A \beta$ in the brain tissue after TSA treatment. This result indicated that TSA might promote albumin-mediated the transport of $A \beta$ to periphery through the blood vessels. Therefore, we further examined the level of $A \beta$-albumin complexes in plasma and found that the level of $A \beta$ albumin complexes in plasma decreased after TSA treatment in APP/PS1 mice (Fig. S6C), which is consistent with the changes of $A \beta$ and $A \beta$-albumin complexes in the brain. This finding not only confirmed the interaction between $A \beta$ and albumin, but also suggested a close relationship between the levels of $A \beta$ in the central brain and peripheral plasma after chronic TSA treatment.

To further verify the above results, we then detected the effects of TSA on the levels of albumin and A $\beta$ oligomer in bEnd.3 cells (endothelial cells) by Western blot. As shown in Fig. 3c, d, the expression of albumin in bEnd.3 cells was upregulated in the presence of $\mathrm{A} \beta_{42}(p<0.05)$, while that was much higher in co-application of $A \beta_{42}$ and TSA $(p<0.001)$. The high expression of albumin by TSA 


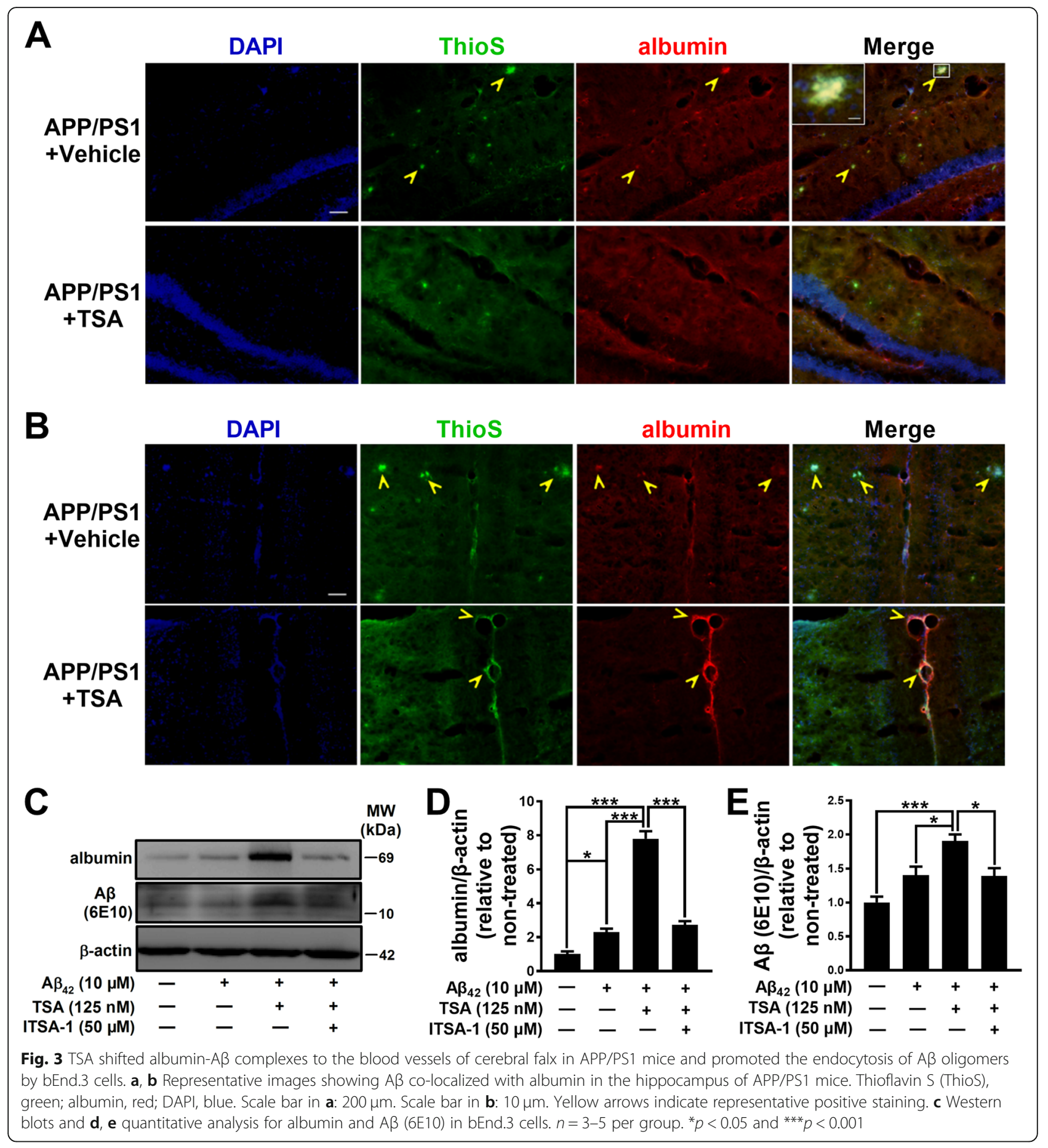

was reversed by ITSA-1, a specific inhibitor of TSA $(p<$ 0.001 ). Furthermore, the endocytosis of $A \beta$ oligomers by bEnd.3 cells was enhanced more prominently in $A \beta_{42}+$ TSA group than $\mathrm{A} \beta_{42}$ alone group $(p<0.05)$, whereas that was markedly attenuated in $\mathrm{A} \beta_{42}+$ TSA + ITSA-1 group $(p<0.05)$ (Fig. 3e). These findings suggest that TSA treatment increased albumin level and promoted the endocytosis of $\mathrm{A} \beta$ oligomers in bEnd. 3 cells.
TSA dramatically elevated the albumin expression in microglia, inhibited $A \beta$ aggregation, and promoted phagocytosis of $A \beta$ oligomers

Microglia, as the primary innate immune cells, have been demonstrated to play a prominent role in $A \beta$ clearance by their phagocytosis in the brain [25], and albumin is also expressed at mRNA and protein levels in human microglia [26]. Here, we further investigated the effects 
of TSA on the level of albumin and the phagocytosis of $\mathrm{A} \beta$ in BV2 cells (microglia cells). Western blot analysis revealed that albumin was mainly expressed in BV2 cells compared to N2a and HT22 cells (Fig. 4a), and the albumin levels in BV2 cells increased with the increase of TSA concentrations $(60 \mathrm{nM}: p<0.05,125 \mathrm{nM}: p<0.01,250$ nM: $p<0.01$ ), with maximal effect observed at $125 \mathrm{nM}$ (Fig. 4b). The levels of albumin in BV2 cells also increased with the increase of TSA $(125 \mathrm{nM})$ treatment time $(24 \mathrm{~h}$ : $p<0.05,36 \mathrm{~h}: p<0.01$ ) (Fig. 4c). The dose- and timedependent increase of albumin expression by TSA can be also reversed by a specific TSA inhibitor ITSA-1 $(p<$
$0.05)$. These data clearly confirmed that TSA greatly enhanced the expression of albumin in BV2 cells.

In light of the above findings, we supposed that mouse albumin might directly affect the aggregation of $A \beta$. TEM images showed that the incubation of $A \beta_{42}$ with mouse albumin resulted in a dramatic inhibition for the $\mathrm{A} \beta$ fibril formation compared with $\mathrm{A} \beta_{42}$ alone (Fig. 4d). Western blot analysis showed that mouse albumin apparently reduced neurotoxic $\mathrm{A} \beta$ oligomers $(p<0.05)$ (Fig. 4e, f). These findings suggested that mouse albumin could directly bind to $A \beta$ and effectively inhibit $A \beta$ aggregation.

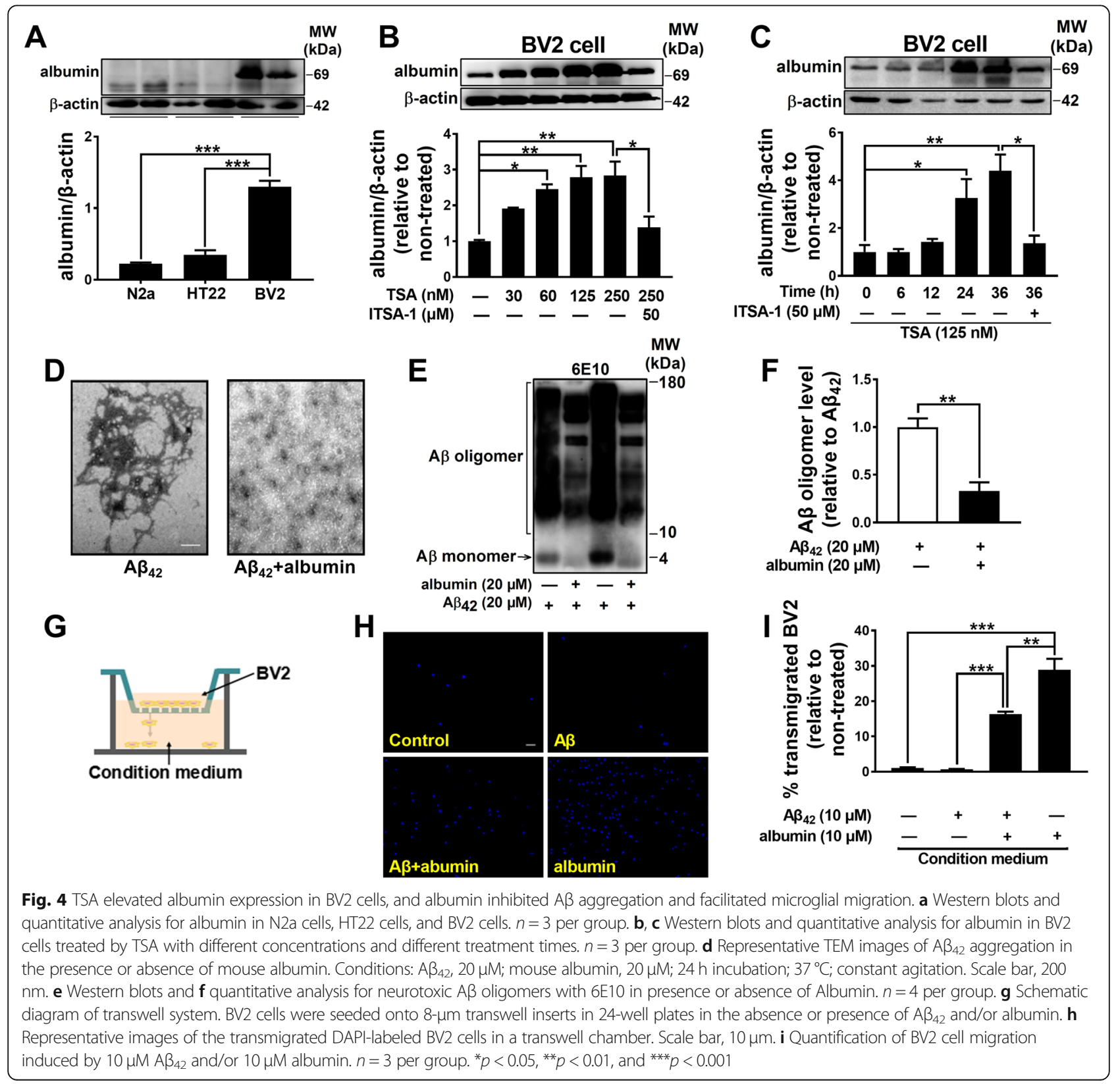


The interaction of albumin with $A \beta$ and the cluster of microglia around $\mathrm{A} \beta$ plaques in the APP/PS1 mice strongly suggested that albumin might be involved in the migration and phagocytosis of microglia. To validate this hypothesis, the effects of albumin on BV2 cell migration were firstly detected using an in vitro transwell system. As illustrated in Fig. 4g-i, the migration of BV2 cells was slightly inhibited by $\mathrm{A} \beta(p>0.05)$, while albumin evidently increased BV2 cell migration $(p<0.01)$ and reversed the inhibitory effects of $A \beta(p<0.001)$, indicating that the combination of albumin and $A \beta$ facilitated microglial migration to $A \beta$. Further, we observed the morphological changes and the phagocytosis of BV2 cells in the presence of $A \beta$ and TSA. As shown in Fig. 5a, $\mathrm{b}$, normal BV2 cells were mostly round or long with a ratio about $50 \%$, while $\mathrm{A} \beta$-treated BV2 cells displayed more round shape with less and shorter pseudopodia $(p<0.05)$. In the presence of TSA, the pseudopodia of BV2 cells became more and longer even with the same concentration of $A \beta_{42}(p<0.01)$, while this effect of TSA could be inhibited by TSA inhibitor ITSA-1 $(p<0.01)$. In concordance with this, TSA treatment promoted microglia to adopt a ramified shape and increased their pseudopodia in the hippocampus of APP/PS1 mice (Fig. 5c). The increase of pseudopodia indicates the enhancement of phagocytic ability of BV2 cells [27]. To further assess the effects of TSA on $A \beta$ phagocytosis in BV2 cells, we next examined the levels of intracellular $\mathrm{A} \beta$ oligomers, albumin, and Ac- $\mathrm{H} 4$ by Western blot. As shown in Fig. $5 \mathrm{~d}-\mathrm{g}$, compared to $\mathrm{A} \beta_{42}$ alone treatment, co-application of TSA and $A \beta_{42}$ not only upregulated the levels of albumin $(p<0.05)$ and Ac-H4 $(p<0.001)$, but also significantly elevated $\mathrm{A} \beta$ oligomers $(p<0.01)$ in BV2 cells. All of these elevations induced by TSA were also markedly suppressed by ITSA- $1(p<0.05$ or $p<$ $0.001)$. These results above indicated that TSA treatment structurally and functionally promoted the phagocytosis of $A \beta$ oligomers by $B V 2$ cells.

\section{Discussion}

The present study confirmed that chronic administration of TSA could ameliorate the short-term and long-term memory of APP/PS1 mice simultaneously in novel object recognition and Morris water maze tests. These behavioral findings further complemented previous experimental researches [15, 28, 29] and supported our results from big data analysis that TSA might be a potential anti-AD drug. As a key feature of $\mathrm{AD}, \mathrm{A} \beta$ deposition is mainly located in the brain regions involved in cognitive functions, particularly the hippocampus [4], which caused deterioration of the ability of those brain regions to orchestrate cognition. At present, there are several divergent reports on the effects of TSA on A $\beta$ deposition. For example, Yang et al.'s reports showed that administration of TSA in APP/PS1 mice prevented the formation of new $A \beta$ deposition but increased the size of existing plaques [16]. Prasad and colleagues found that TSA was conducive to phagocytose $A \beta$ by astrocytes [30]. Similarly, several studies also found that TSA analogs reduced A $\beta$ deposition [31, 32]. Here, we

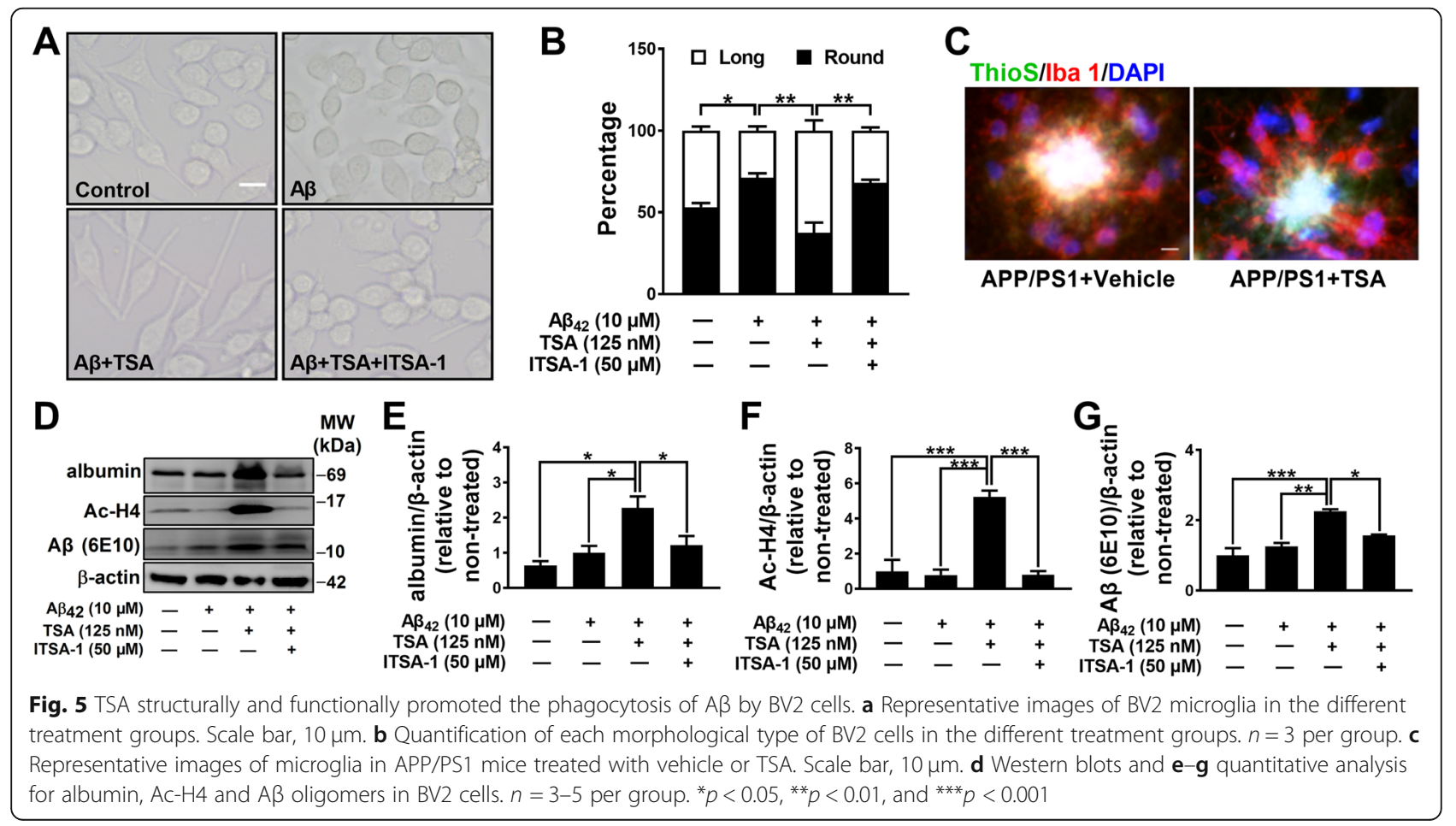


employed multiple experimental techniques to detect the $A \beta$ in the brain of mice. By combined application of ThioS staining and $A \beta$ immunostaining (6E10), we demonstrated that TSA could significantly reduce the number and area percentage of $\mathrm{A} \beta$ plaques in the hippocampus of APP/PS1 mice. Considering that A $\beta$ plaques maybe only reflect the levels of those insoluble aggregated $A \beta$ fibrils, not including soluble neurotoxic $\mathrm{A} \beta$ oligomers, we performed immumoblotting with $6 \mathrm{E} 10$ and D54D2 antibodies to detect soluble $A \beta$ level of mice and found that TSA effectively decreased the level of hippocampal soluble $A \beta$, presumably $A \beta$ oligomers, in the APP/PS1 mice. Then, by using ultra-sensitive Simoa assay, our data revealed that TSA treatment decreased both $A \beta_{40}$ and $A \beta_{42}$, two major forms of $A \beta$, in the hippocampus of APP/PS1 mice. These findings indicated that TSA not only reduced the $A \beta$ plaques but also decreased the levels of presumable $A \beta$ oligomers in the hippocampus of APP/PS1 mice. In addition, the present study also found that TSA treatment significantly alleviated abnormal microglial proliferation in the hippocampus of APP/PS1 mice. Since microglial proliferation has been also recognized as a characteristic of $\mathrm{AD}$ in humans and blocking microglial proliferation can improve short-term memory and synaptic density in the hippocampus of APP/PS1 [33], we supposed that the reductions of $A \beta$ level and microglial proliferation in the brain might contribute to the TSA-induced improvement of cognitive behaviors in the APP/PS1 mice. These pathological findings established a solid foundation for the follow-up molecular researches.

The imbalance between $A \beta$ production and $A \beta$ clearance results in $A \beta$ accumulation and aggregation in the brain [34]. So, the potential mechanisms for TSA decreasing $A \beta$ accumulation in the brain might refer to the inhibition of excess $A \beta$ production and/or the promotion of $A \beta$ degradation and clearance. To clarify the principles of TSA in decreasing A $\beta$, we examined the expression levels of the proteins associated with amyloidogenic processing, $A \beta$ degradation, and $A \beta$ transport. Our results demonstrated that TSA did not affect the levels of flAPP, CTF, and BACE1 in the hippocampus of APP/ PS1 mice, which is consistent with Yang et al.' observations [17], suggesting that TSA did not target A $\beta$ producing activity but rather $A \beta$ clearance. It is known that the clearance of $A \beta$ from the brain is involved in several mechanisms, including enzymatic degradation, uptake by microglial or astrocytic phagocytosis, proteasome degradation, and peripheral clearance. The first, extracellular $A \beta$ can be rapidly degraded by several enzymes, such as NEP and IDE. However, there was no significant difference in the levels of IDE and NEP in mouse hippocampus among groups, suggesting that TSA did not affect the enzymatic degradation pathway of $A \beta$. Secondly, $A \beta$ is also degraded by two major intracellular pathways, UPP and ALP. Although previous studies found that TSA was able to induce autophagy $[18,35,36]$, we did not find any significant change in the levels of autophagy-related proteins in the hippocampus of mice by TSA. Instead, we found that TSA slightly increased the level of monomeric ubiquitin in the hippocampus of WT mice, which shared a number of similarities with Tian et al.'s [37] findings that chronic TSA treatment increased monomeric ubiquitin level, including ubiquitin $\mathrm{B}$ and ubiquitin $\mathrm{A}$. We also justified that APP/PS1 mice had a much higher level of ubiquitin monomer relative to WT mice, which was in line with previous results by Tseng and colleagues [38] in which proteasomal dysfunction resulted in the increases of $A \beta$ accumulation and monomeric ubiquitin in $\mathrm{AD}$ mice brains. We noticed that TSA treatment significantly decreased the level of ubiquitin monomer in the hippocampus of APP/PS1 mice, suggesting that TSA might be through UPP to reduce $A \beta$ level, thereby decreasing the level of ubiquitin monomer. In addition, according to the "peripheral $A \beta$ sink" hypothesis, $A \beta$ between the brain and periphery is in equilibrium. Reduction of peripheral $A \beta$ would help with the efflux of central $A \beta$ in the brain or cerebrospinal fluid (CSF) [39-41]. Our results by Simoa assay disclosed that chronic TSA treatment significantly decreased the levels of $A \beta_{40}$ and $A \beta_{42}$ in plasma of APP/PS1 mice. So, we speculated that the peripheral clearance is at least partially involved in the reduction of central A $\beta$ induced by TSA. But what mediated the transport of $A \beta$ from brain to periphery?

In the present study, we firstly examined the expression level of LRP1, a main cell surface transporter protein participated in both $A \beta$ endocytosis and transcytosis across the BBB [42-44]. But no significant change in LRP1 level was found among groups. In light of that $A \beta$ transport depends on the interaction between $A \beta$ and variety proteins $[45,46]$, interestingly, our Co-IP and LC-MS/MS analysis indicated that there was a close interaction between albumin and $A \beta$ in the hippocampus of APP/PS1 mice. Furthermore, we found that hippocampal albumin-A $\beta$ complexes decreased with the decrease of $A \beta$ after TSA treatment in APP/PS1 mice. This may be related to the interaction of proteins and the transportation of albumin. Albumin is mainly synthesized in the liver, with high ligand binding and transport capacity [24, 47-50]. Hence, we speculated that albumin, as an important protein carrier, might be involved in the transport of $A \beta$ during the treatment with TSA. To verify this hypothesis, we performed double immunofluorescence staining and demonstrated that a large number of albumin- $A \beta$ complexes were shifted to and clustered in the blood vessels around cerebral falx in APP/PS1 mice after TSA treatment, implying that 
TSA-induced $A \beta$ clearance is most likely mediated by the combination and transportation of albumin. So, the levels of albumin and $A \beta$ in the hippocampus should be dynamic, depending on the TSA treatment. Indeed, we found that the expression levels of albumin and $A \beta$ decreased in the hippocampus of APP/PS1 mice while both of them increased around brain blood vessels after chronic treatment with TSA. Considering the dynamic changes of $A \beta$-albumin complexes with clearance and transfer of $A \beta$ after long-term TSA treatment in vivo, we proposed that the early elevated $A \beta$-albumin complexes in hippocampus might be transported to the periphery. Hence, the expression level of albumin bound to $A \beta$ decreased with the clearance of $A \beta$ in the hippocampus. In addition, our studies revealed that treatment of bEnd.3 cells with TSA significantly upregulated albumin level and enhanced the endocytosis of $A \beta$, further supporting the hypothesis that the TSA-induced high expression of albumin in endothelial cells may be beneficial to combining and transporting $A \beta$ across cerebral blood vessels toward the periphery in APP/PS1 mice. That is also why albumin- $A \beta$ complexes were vastly concentrated around cerebral blood vessels in TSA-treated APP/PS1 mice.

Albumin is not only a high-abundance protein in plasma, but also a major component of most extracellular fluids including CSF, interstitial fluid (ISF) and lymph [51-54]. It has multifunctional properties including transportation of hormones, fatty acids, drugs, and metabolites, protective action on neuronal and glia cells, antioxidant activity, and anti-inflammatory activity [55, 56]. Owing to its multi-functionality, albumin has been implicated in many disease conditions of the brain, including AD. Extensive evidences have shown that albumin has a high affinity for $A \beta$, which can bind to and transport around $90 \%$ circulating $A \beta$. It is worth noting that a lower serum albumin concentration has been reported in AD patients, compared to those healthy counterparts $[57,58]$. Several clinical studies also showed that plasma exchange with human albumin or intravenous administration of albumin ameliorated cerebral pathology, memory behavior, and language functions in AD patients [58-60]. These facts correlate well the decreased plasma albumin with the accumulated central $A \beta$, being consistent with "peripheral $A \beta$ sink" hypothesis and suggesting that albumin might be a new target for the clearance of $A \beta$. Interestingly, Vanhaecke reported that TSA induced a higher albumin secretion in cultured rat hepatocytes from 7th day after TSA treatment [61]. Accordingly, we speculate that the peripheral effects of TSA might also play an important role in the central $A \beta$ clearance. The chronic treatment with TSA in the present in vivo study might elevate the plasma albumin level in AD mice, which could be beneficial for $\mathrm{A} \beta$ binding, transportation, and clearance in the periphery. Indeed, our further experiments demonstrated that the levels of both $A \beta$ and $A \beta$-albumin complexes in plasma were all declined by chronic TSA treatment in APP/PS1 mice. Of course, the detailed mechanisms involved in plasma $A \beta$ clearance by TSA are still to be investigated.

Microglia, the primary innate immune effector cells in the CNS, rapidly activate upon encountering tissue damage or injury and transform into active phagocytic microglia with high capacity for phagocytic removal of cellular debris or damaged neurons $[62,63]$. It has been reported that microglial phagocytosis of $A \beta$ was impaired in the brains of $\mathrm{AD}$ patients and $\mathrm{AD}$ mouse models [64]. Therefore, the enhancement of microglial phagocytic activity to clear $A \beta$ deposits plays an important role in AD progression. Ahn et al. found that microglia could synthesize albumin in the human brain [26], but its function and regulation mechanism remain unclear. Based on these issues, by using Western blot and different cell lines including N2a mouse neuroblastoma cells, HT22 murine hippocampal neuronal cells and BV2 murine microglial cells, we compared the expression levels of albumin in these cell lines. As expected, albumin was mainly expressed in BV2 cells, and TSA treatment enhanced albumin expression of BV2 cells in a dose- and time-dependent manner, while these effects could be repressed by ITSA-1. Moreover, albumin can also prevent $A \beta$ polymerization [47]. As mentioned by Choi [21] and Picón-Pagès [65], human serum albumin suppressed $A \beta$ aggregation by binding to the oligomeric or polymeric $A \beta$ and blocking a further addition of peptide and attenuated $A \beta$ neurotoxicity. We also confirmed that mouse albumin directly bound to $A \beta$ and efficiently suppressed the formation of $A \beta$ fibrils, suggesting that the antagonistic effects of TSA on A $\beta$-induced neurotoxicity was mediated by elevating albumin expression in mouse brain microglia, which then bound to $A \beta$ and prevented its aggregation. Considering the fact that microglia always surround $A \beta$ plaques, we wondered that whether the microglia expressed albumin induced microglia migration to $A \beta$. The transwell migration assay clearly indicated that albumin, rather than $A \beta$, indeed promoted the migration of BV2 cells. These findings indicated that $A \beta$ plaque itself did not induce the migration and aggregation of microglia, the microglial migration and aggregation might be mediated by some protein binding to $A \beta$, such as albumin. The combination of albumin and $A \beta$ might be important and necessary in the microglial migration to $A \beta$ and the microglial phagocytosis of $A \beta$. It is possible that albumin acts as a signal molecule in $A \beta$ recognition and mediates the phagocytosis and clearance of $A \beta$ by microglia. Indeed, our in vitro Western blot with cultured microglia showed that TSA treatment not only upregulated the 
levels of albumin and acetylated histone $\mathrm{H} 4$, which is in accordance with Takuma et al.'s findings that the acetylation of histone H3K14 was increased by TSA in PC12 cell [66], but also increased the microglia pseudopodia and enhanced the phagocytosis of A $\beta$ in APP/PS1 mice.

\section{Limitations for this study}

Our current study has some limitations. Although our study showed that TSA, as a HDAC inhibitor, could promote $A \beta$ clearance by elevating albumin expression in microglia and microvascular endothelial cells, the precise signaling pathways that are involved in the upregulation of albumin by TSA remain to be elucidated. Additionally, cognitive impairments and AD-related pathology were improved in an $\mathrm{AD}$ animal model through chronic TSA treatment. However, the therapeutic benefit of this in patients with AD remains unknown. Further clinical trials are needed to confirm our results.

\section{Conclusions}

In summary, this study further confirmed that TSA could effectively improve the cognitive behaviors and AD-like pathology in APP/PS1 mice. We systematically explore the effects of TSA on A $\beta$ clearance pathways and find that the mechanisms underlying the protective roles of TSA are mainly involved in the enhancement of phagocytosis of $A \beta$ by microglia and the promotion of endocytosis of $A \beta$ by microvascular endothelial cells. Moreover, the upregulation of albumin by TSA plays important mediating roles in the $A \beta$ clearance including promoting $A \beta$ transport, preventing $A \beta$ aggregation, and inducing microglia migration to $\mathrm{A} \beta$ (Fig. S7). The study uncovered a new mechanism for TSA in modulation of $A \beta$ clearance and suggested that TSA would be an ideal candidate for further clinical tests as a therapeutic medicine of AD.

\section{Supplementary Information}

The online version contains supplementary material available at https://doi. org/10.1186/s13195-020-00746-8.

Additional file 1. Supplementary Information accompanies this paper on the Alzheimer's Research \& Therapy website (https://alzres. biomedcentral.com)

\footnotetext{
Abbreviations

AD: Alzheimer's disease; A 3 : Amyloid $\beta$; TSA: Trichostatin A; HDAC: Histone deacetylase; LTP: Long-term potentiation; NOI: Novel object recognition index; Simoa: Single molecule array; Co-IP: Co-immunoprecipitation; LC-MS/ MS: Liquid chromatography-tandem mass spectrometry; APP: Amyloid precursor protein; flAPP: Full-length amyloid precursor protein; CTF: Cterminal fragment; BACE1: $\beta$-site APP cleaving enzyme 1; UPP: Ubiquitinproteasome pathway; ALP: Autophagy-lysosome pathway; NEP: Neprilysin; IDE: Insulin-degrading enzyme; LRP1: Low-density lipoprotein receptorrelated protein 1; Ac-H4: Acetylated histone H4; ISF: Interstitial fluid; CSF: Cerebrospinal fluid; BBB: Blood brain barrier
}

\section{Acknowledgements}

Not applicable.

\section{Authors' contributions}

J-SQ and P-FH designed the research. QS and TL conducted the experiments, performed data analysis, and wrote the manuscript. Q-CG and DY participated in a part of the experiments. Z-JW, M-NW, and QY provided technical support. J-SQ and X-CL revised the manuscript. All of the authors have read and approved the final manuscript.

\section{Funding}

This study was supported by the grants from National Natural Science Foundation of China (No. 31471080), Shanxi "1331 Project" Key Subjects Construction (1331KSC), Fund Program for "Sanjin Scholars" of Shanxi Province, and Shanxi Province Science Foundation for Excellent Young Scholars (No. 201801D211005).

\section{Availability of data and materials}

All data generated in this study are available from the corresponding author on reasonable request.

\section{Ethics approval and consent to participate}

All animal experiments in this study were carried out in accordance with the recommendations of the National Institute of Health Guide for the Care and Use of Laboratory Animals. The study protocols were approved by the Animal Ethics Committee Of Shanxi Medical University (Taiyuan, China)

\section{Consent for publication}

Not applicable.

\section{Competing interests}

The authors declare that no actual or potential conflict of interest.

Received: 24 June 2020 Accepted: 8 December 2020

Published online: 04 January 2021

\section{References}

1. Patterson C. World Alzheimer Report 2018-the state of the art of dementia research: new frontiers. Alzheimer's Dis Int. 2018:1-48.

2. Alzheimer's Association. 2019 Alzheimer's disease facts and figures. Alzheimers Dement. 2019;15(3):321-87.

3. Forner S, Baglietto-Vargas D, Martini AC, Trujillo-Estrada L, LaFerla FM. Synaptic impairment in Alzheimer's disease: a dysregulated symphony. Trends Neurosci. 2017:40(6):347-57.

4. Hardy J, Selkoe DJ. The amyloid hypothesis of Alzheimer's disease: progress and problems on the road to therapeutics. Science. 2002;297(5580):353-6.

5. Vassar R, Bennett BD, Babu-Khan S, Kahn S, Mendiaz EA, Denis P, et al. Betasecretase cleavage of Alzheimer's amyloid precursor protein by the transmembrane aspartic protease BACE. Science. 1999:286(5440):735-41.

6. De Strooper B, Saftig P, Craessaerts K, Vanderstichele H, Guhde G, Annaert $W$, et al. Deficiency of presenilin-1 inhibits the normal cleavage of amyloid precursor protein. Nature. 1998;391(6665):387-90.

7. Xin SH, Tan L, Cao X, Yu JT, Tan L. Clearance of amyloid beta and tau in Alzheimer's disease: from mechanisms to therapy. Neurotox Res. 2018;34(3): 733-48.

8. Nalivaeva NN, Turner AJ. Targeting amyloid clearance in Alzheimer's disease as a therapeutic strategy. Br J Pharmacol. 2019;176(18):3447-63.

9. Tarasoff-Conway JM, Carare RO, Osorio RS, Glodzik L, Butler T, Fieremans E, et al. Clearance systems in the brain-implications for Alzheimer disease. Nat Rev Neurol. 2015;11(8):457-70.

10. Zhao $Y$, Wu X, Li X, Jiang LL, Gui X, Liu Y, et al. TREM2 is a receptor for $\beta$ amyloid that mediates microglial function. Neuron. 2018;97(5):1023-31.e7.

11. Talevi A, Bellera CL. Challenges and opportunities with drug repurposing: finding strategies to find alternative uses of therapeutics. Expert Opin Drug Discov. 2020;15(4):397-401.

12. Tsuji N, Kobayashi M, Nagashima K, Wakisaka $Y$, Koizumi K. A new antifungal antibiotic, trichostatin. J Antibiot (Tokyo). 1976;29(1):1-6.

13. Vigushin DM, Ali S, Pace PE, Mirsaidi N, Ito K, Adcock I, et al. Trichostatin A is a histone deacetylase inhibitor with potent antitumor activity against breast cancer in vivo. Clin Cancer Res. 2001;7(4):971-6. 
14. Johnstone RW. Histone-deacetylase inhibitors: novel drugs for the treatment of cancer. Nat Rev Drug Discov. 2002;1 (4):287-99.

15. Francis $\mathrm{Yl}$, Fa M, Ashraf H, Zhang H, Staniszewski A, Latchman DS, et al. Dysregulation of histone acetylation in the APP/PS1 mouse model of Alzheimer's disease. J Alzheimers Dis. 2009;18(1):131-9.

16. Yang W, Chauhan A, Mehta S, Mehta P, Gu F, Chauhan V. Trichostatin A increases the levels of plasma gelsolin and amyloid beta-protein in a transgenic mouse model of Alzheimer's disease. Life Sci. 2014;99(1-2):31-6.

17. Yang W, Chauhan A, Wegiel J, Kuchna I, Gu F, Chauhan V. Effect of trichostatin A on gelsolin levels, proteolysis of amyloid precursor protein, and amyloid beta-protein load in the brain of transgenic mouse model of Alzheimer's disease. Curr Alzheimer Res. 2014;11(10):1002-11.

18. Li LH, Peng WN, Deng Y, Li JJ, Tian XR. Action of trichostatin A on Alzheimer's disease-like pathological changes in SH-SY5Y neuroblastoma cells. Neural Regen Res. 2020;15(2):293-301.

19. Leger M, Quiedeville A, Bouet V, Haelewyn B, Boulouard M, Schumann-Bard $P$, et al. Object recognition test in mice. Nat Protoc. 2013;8(12):2531-7.

20. Vorhees CV, Williams MT. Morris water maze: procedures for assessing spatial and related forms of learning and memory. Nat Protoc. 2006;1(2): 848-58.

21. Choi TS, Lee HJ, Han JY, Lim MH, Kim HI. Molecular insights into human serum albumin as a receptor of amyloid- $\beta$ in the extracellular region. J Am Chem Soc. 2017;139(43):15437-45.

22. Araujo DM, Cotman CW. Beta-amyloid stimulates glial cells in vitro to produce growth factors that accumulate in senile plaques in Alzheimer's disease. Brain Res. 1992;569(1):141-5.

23. Sutcliffe JG, Hedlund PB, Thomas EA, Bloom FE, Hilbush BS. Peripheral reduction of $\beta$-amyloid is sufficient to reduce brain $\beta$-amyloid: implications for Alzheimer's disease. J Neurosci Res. 2011;89(6):808-14.

24. Mercuriali F, Inghilleri G. Albumin: is it a play-maker, a carrier or both? Anaesthesia, Pain, Intensive Care and Emergency Medicine — APICE; 1999. Milano: Springer Milan; 1999.

25. Gehrmann J, Matsumoto Y, Kreutzberg GW. Microglia: intrinsic immuneffector cell of the brain. Brain Res Brain Res Rev. 1995;20(3):269-87.

26. Ahn SM, Byun K, Cho K, Kim JY, Yoo JS, Kim D, et al. Human microglial cells synthesize albumin in brain. Plos One. 2008;3(7):e2829.

27. Zhou R, Shi XY, Bi DC, Fang WS, Wei GB, Xu X. Alginate-derived oligosaccharide inhibits neuroinflammation and promotes microglial phagocytosis of $\beta$-amyloid. Mar Drugs. 2015;13(9):5828-46.

28. Wang BY, Zhong Y, Zhao Z, Miao Y. Epigenetic suppression of hippocampal BDNF mediates the memory deficiency induced by amyloid fibrils. Pharmacol Biochem Behav. 2014;126:83-9.

29. Rumbaugh G, Sillivan SE, Ozkan ED, Rojas CS, Hubbs CR, Aceti M, et al. Pharmacological selectivity within class I histone deacetylases predicts effects on synaptic function and memory rescue. Neuropsychopharmacology. 2015;40(10):2307-16.

30. Prasad H, Rao R. Amyloid clearance defect in ApoE4 astrocytes is reversed by epigenetic correction of endosomal pH. Proc Natl Acad Sci U S A. 2018 115(28):E6640-E9.

31. Janczura KJ, Volmar CH, Sartor GC, Rao SJ, Ricciardi NR, Lambert G, et al. Inhibition of HDAC3 reverses Alzheimer's disease-related pathologies in vitro and in the 3xTg-AD mouse model. Proc Natl Acad Sci U S A. 2018; 115(47):E11148-E57.

32. Zhang L, Liu C, Wu J, Tao JJ, Sui XL, Yao ZG, et al. Tubastatin A/ACY-1215 improves cognition in Alzheimer's disease transgenic mice. J Alzheimers Dis. 2014;41(4):1193-205.

33. Olmos-Alonso A, Schetters ST, Sri S, Askew K, Mancuso R, Vargas-Caballero $M$, et al. Pharmacological targeting of CSF1R inhibits microglial proliferation and prevents the progression of Alzheimer's-like pathology. Brain. 2016; 139(Pt 3):891-907.

34. Hyman BT, Marzloff $K$, Arriagada PV. The lack of accumulation of senile plaques or amyloid burden in Alzheimer's disease suggests a dynamic balance between amyloid deposition and resolution. J Neuropathol Exp Neurol. 1993;52(6):594-600.

35. Wu N, Zhu Y, Xu X, Zhu Y, Song Y, Pang $L$, et al. The anti-tumor effects of dual PI3K/mTOR inhibitor BEZ235 and histone deacetylase inhibitor Trichostatin A on inducing autophagy in esophageal squamous cell carcinoma. J Cancer. 2018;9(6):987-97.

36. Zhang J, Ng S, Wang J, Zhou J, Tan SH, Yang N, et al. Histone deacetylase inhibitors induce autophagy through FOXO1-dependent pathways. Autophagy. 2015;11(4):629-42.
37. Tian Y, Ding W, Wang Y, Ji T, Sun S, Mo Q, et al. Ubiquitin B in cervical cancer: critical for the maintenance of cancer stem-like cell characters. Plos One. 2013;8(12):e84457.

38. Tseng BP, Green KN, Chan JL, Blurton-Jones M, LaFerla FM. Abeta inhibits the proteasome and enhances amyloid and tau accumulation. Neurobiol Aging. 2008;29(11):1607-18.

39. Zhang $Y$, Lee DH. Sink hypothesis and therapeutic strategies for attenuating abeta levels. Neuroscientist. 2011;17(2):163-73.

40. Liu YH, Wang YR, Xiang Y, Zhou HD, Giunta B, Manucat-Tan NB, et al. Clearance of amyloid-beta in Alzheimer's disease: shifting the action site from center to periphery. Mol Neurobiol. 2015;51(1):1-7.

41. DeMattos RB, Bales KR, Cummins DJ, Dodart JC, Paul SM, Holtzman DM. Peripheral anti-Abeta antibody alters CNS and plasma Abeta clearance and decreases brain Abeta burden in a mouse model of Alzheimer's disease. Proc Natl Acad Sci U S A. 2001:98(15):8850-5.

42. Van Gool B, Storck SE, Reekmans SM, Lechat B, Gordts P, Pradier L, et al. LRP1 has a predominant role in production over clearance of $A \beta$ in a mouse model of Alzheimer's disease. Mol Neurobiol. 2019;56(10):7234-45.

43. Storck SE, Meister S, Nahrath J, Meissner JN, Schubert N, Di Spiezio A, et al. Endothelial LRP1 transports amyloid- $\beta(1-42)$ across the blood-brain barrier. J Clin Invest. 2016;126(1):123-36.

44. Kanekiyo T, Cirrito JR, Liu CC, Shinohara M, Li J, Schuler DR, et al. Neuronal clearance of amyloid- $\beta$ by endocytic receptor LRP1. J Neurosci. 2013;33(49): 19276-83.

45. Deane R, Wu Z, Sagare A, Davis J, Du Yan S, Hamm K, et al. LRP/amyloid beta-peptide interaction mediates differential brain efflux of Abeta isoforms. Neuron. 2004;43(3):333-44.

46. Wilhelmus MM, de Waal RM, Verbeek MM. Heat shock proteins and amateur chaperones in amyloid-beta accumulation and clearance in Alzheimer's disease. Mol Neurobiol. 2007:35(3):203-16.

47. Biere AL, Ostaszewski B, Stimson ER, Hyman BT, Maggio JE, Selkoe DJ. Amyloid beta-peptide is transported on lipoproteins and albumin in human plasma. J Biol Chem. 1996;271(51):32916-22

48. Hamashima $\mathrm{Y}$, Harter JG, Coons $\mathrm{AH}$. The localization of albumin and fibrinogen in human liver cells. J Cell Biol. 1964;20(2):271-9.

49. Hassan M, Azzazy E, Christenson RH. All about albumin: biochemistry, genetics, and medical applications. Theodore Peters, Jr. San Diego, CA: Academic Press, 1996, 432 pp, \$85.00. ISBN 0-12-552110-3. Clin Chem. 1997; 43(10):2014a-5.

50. Tilghman SM, Belayew A. Transcriptional control of the murine albumin/ alpha-fetoprotein locus during development. Proc Natl Acad Sci U S A. 1982;79(17):5254-7.

51. Yuan X, Russell T, Wood G, Desiderio DM. Analysis of the human lumbar cerebrospinal fluid proteome. Electrophoresis. 2002;23(7-8):1185-96.

52. Interewicz B, Olszewski WL, Leak LV, Petricoin EF, Liotta LA. Profiling of normal human leg lymph proteins using the 2-D electrophoresis and SELDITOF mass spectrophotometry approach. Lymphology. 2004;37(2):65-72.

53. Celis JE, Gromov P, Cabezon T, Moreira JM, Ambartsumian N, Sandelin K, et al. Proteomic characterization of the interstitial fluid perfusing the breast tumor microenvironment: a novel resource for biomarker and therapeutic target discovery. Mol Cell Proteomics. 2004;3(4):327-44.

54. Ahn SM, Simpson RJ. Body fluid proteomics: prospects for biomarker discovery. Proteomics Clin Appl. 2007;1 (9):1004-15.

55. Garcovich M, Zocco MA, Gasbarrini A. Clinical use of albumin in hepatology. Blood Transfus. 2009;7:268-77.

56. Evans TW. Review article: albumin as a drug--biological effects of albumin unrelated to oncotic pressure. Aliment Pharmacol Ther. 2002;16(Suppl 5):6-11.

57. Kim TS, Pae CU, Yoon SJ, Jang WY, Lee NJ, Kim JJ, et al. Decreased plasma antioxidants in patients with Alzheimer's disease. Int J Geriatr Psychiatry. 2006:21(4):344-8.

58. Zhong $X$, Liao $Y$, Chen $X$, Mai N, Ouyang $C$, Chen B, et al. Abnormal serum bilirubin/albumin concentrations in dementia patients with abeta deposition and the benefit of intravenous albumin infusion for Alzheimer's disease treatment. Front Neurosci. 2020;14:859.

59. Boada M, Anaya F, Ortiz P, Olazaran J, Shua-Haim JR, TO O, et al. Efficacy and safety of plasma exchange with $5 \%$ albumin to modify cerebrospinal fluid and plasma amyloid- $\beta$ concentrations and cognition outcomes in Alzheimer's disease patients: a multicenter, randomized, controlled clinical trial. J Alzheimers Dis. 2017;56(1):129-43.

60. Boada M, Lopez O, Nunez L, Szczepiorkowski ZM, Torres M, Grifols C, et al. Plasma exchange for Alzheimer's disease management by albumin 
replacement (AMBAR) trial: study design and progress. Alzheimers Dement (N Y). 2019;5:61-9.

61. Vanhaecke T, Henkens T, Kass GE, Rogiers V. Effect of the histone deacetylase inhibitor trichostatin $\mathrm{A}$ on spontaneous apoptosis in various types of adult rat hepatocyte cultures. Biochem Pharmacol. 2004;68(4):753-60.

62. Mandrekar S, Jiang Q, Lee CY, Koenigsknecht-Talboo J, Holtzman DM, Landreth GE. Microglia mediate the clearance of soluble Abeta through fluid phase macropinocytosis. J Neurosci. 2009;29(13):4252-62.

63. Norden DM, Godbout JP. Review: microglia of the aged brain: primed to be activated and resistant to regulation. Neuropathol Appl Neurobiol. 2013; 39(1):19-34.

64. Lucin KM, O'Brien CE, Bieri G, Czirr E, Mosher Kl, Abbey RJ, et al. Microglial beclin 1 regulates retromer trafficking and phagocytosis and is impaired in Alzheimer's disease. Neuron. 2013;79(5):873-86.

65. Picon-Pages P, Bonet J, Garcia-Garcia J, Garcia-Buendia J, Gutierrez D, Valle J, et al. Human albumin impairs amyloid beta-peptide fibrillation through its C-terminus: from docking modeling to protection against neurotoxicity in Alzheimer's disease. Comput Struct Biotechnol J. 2019;17:963-71.

66. Tomioka T, Maruoka H, Kawa H, Yamazoe R, Fujiki D, Shimoke K, et al. The histone deacetylase inhibitor trichostatin A induces neurite outgrowth in PC12 cells via the epigenetically regulated expression of the nur77 gene. Neurosci Res. 2014;88:39-48.

\section{Publisher's Note}

Springer Nature remains neutral with regard to jurisdictional claims in published maps and institutional affiliations.

Ready to submit your research? Choose BMC and benefit from:

- fast, convenient online submission

- thorough peer review by experienced researchers in your field

- rapid publication on acceptance

- support for research data, including large and complex data types

- gold Open Access which fosters wider collaboration and increased citations

- maximum visibility for your research: over $100 \mathrm{M}$ website views per year

At $\mathrm{BMC}$, research is always in progress.

Learn more biomedcentral.com/submissions 